\title{
Secondary prevention of early-onset sepsis: a less invasive Italian approach for managing neonates at risk
}

\author{
Alberto Berardi ${ }^{1,6^{*}}$, Chryssoula Tzialla ${ }^{2}$, Laura Travan ${ }^{3}$, Jenny Bua ${ }^{3}$, Daniele Santori ${ }^{4}$, Milena Azzalli ${ }^{5}$, Caterina Spada ${ }^{6}$, \\ Laura Lucaccioni ${ }^{1}$ and on behalf of the GBS Prevention Working Group of Emilia-Romagna
}

\begin{abstract}
Strategies to prevent early-onset sepsis (EOS) have led to a substantial decline in many countries. However, one of the most controversial topics in neonatology is the management of asymptomatic full-term and late preterm neonates at risk for EOS, and guidelines lack substantial consensus regarding this issue. A strategy for managing neonates, entirely based on serial physical examinations, has been developed in two Italian regions. This strategy seems safe, while reducing laboratory tests and unnecessary antibiotics. In the current commentary we provide area-based data concerning the prevention of EOS in 2 northern Italian regions, and we detail the results of their strategy for managing healthy-appearing newborns at risk for EOS.
\end{abstract}

Keywords: Group B streptococcus, Neonatal sepsis, Intrapartum antibiotic prophylaxis, Newborn infant, Risk factors, Prevention

\section{Background}

Group B streptococcus (GBS) remains a leading cause of early-onset sepsis (EOS, the disease occurring at age 0-6 days) [1]. Intrapartum antibiotic prophylaxis (IAP) is the mainstay of prevention. At the time the first CDC guidelines were issued in the USA during the '90s, cases of GBS-EOS were 3-4/1000 live births, but currently they have declined to fewer than 0.25 per 1000 live birth [2]. However, guidelines for preventing EOS lack substantial consensus regarding the management of asymptomatic neonates at-risk for EOS. [2] CDC guidelines recommend full diagnostic evaluation and antibiotic therapy if signs of sepsis; limited evaluation and antibiotic therapy in case of chorioamnionitis; limited evaluation and observation if preterm birth of prolonged rupture of membrane [1]. However, ancillary laboratory tests have poor predictive value, and

\footnotetext{
* Correspondence: berardi.alberto@policlinico.mo.it

${ }^{1}$ Unità Operativa di Terapia Intensiva Neonatale, Dipartimento Integrato Materno-Infantile, Azienda Ospedaliero-Universitaria Policlinico, Modena, Italy ${ }^{6}$ Scuola di specializzazione in Pediatria, Università di Modena e Reggio Emilia, Azienda Ospedaliero-Universitaria Policlinico, Via del Pozzo, 71 -, 41124 Modena, MO, Italy

Full list of author information is available at the end of the article
}

may result in medical intervention for a large number of uninfected infants [2]. A less invasive approach, entirely based on serial clinical observations is now recommended in some European guidelines [3].

\section{Main text}

The recent national survey [4] shows that the screening-based strategy is largely prevalent and protocols in most centers are consistent with the CDC guidelines [1]. However, differences in GBS EOS sepsis occur among Northern, Central and Southern regions. Furthermore, $75 \%$ of respondent neonatal units would obtain laboratory testing and 91\% would administer empirical antibiotics to full-term and preterm neonates exposed to inadequate IAP, although asymptomatic [4]. This practice is not consistent with the CDC guidelines [1]. Italian epidemiological data, on which to inform recommendations, are still insufficient. Furthermore there is no national laboratory-based surveillance system to tracking serotypes, incidence rates of GBS-EOS, and the impact of perinatal prevention interventions. Nevertheless, area-based data have been obtained prospectively in two northern Italian regions (Emilia-Romagna and Friuli-Venzia Giulia) [5-10]. In Emilia-Romagna, a 
detailed information has been obtained during a 9 years GBS surveillance period [6-10]. In both regions the prevention of EOS relies upon local protocols, mostly consistent with vagino-rectal screening and IAP according to the CDC guidelines (Table 1).

Colonization ranges from 18 to $21 \%$ of pregnant women, [5-10] and up to $\sim 1 / 3$ of them receive IAP. Area-based data on GBS-EOS is available in Emilia-Romagna (from 2003 onwards), and in Friuli-Venezia Giulia (from 2005 to 2006). In both regions incidence rates of GBS-EOS are currently under $0.25 / 1000$ live births.

The case fatality ratio among full-term neonates is close to zero. Both regions recommend no laboratory tests or empirical antibiotics for neonates at-risk for EOS who have an entirely normal physical exam [5, 6]. Their strategy is based on serial physical examinations (SPE), i.e. on vital signs that can be easily detected by medical and non-medical staff. Each examiner fills in and signs at standard intervals a sheet (included in the medical records) detailing general wellbeing, reactivity, spontaneous motility, skin colour (including perfusion) and respiratory signs. Seven (at age 3-6-12-18-24-36-48 h) or 12 visits (at 1, 2, 4, 8, 12, 16, 20, 24, 30, 36, 42, and 48 h) are recommended in Emilia-Romagna and Friuli-Venezia-Giulia respectively. All neonates are left with their own mothers (rooming in), without being admitted to NICU or level II nursery. Every evaluation requires a maximum of 1 to 2 min; nursing staff and midwives give notification to clinicians when signs of illness develop.

During 2005-2006 Cantoni and co-workers compared in Friuli Venezia Giulia 7628 full term neonates managed with the standard approach to 7611 full term newborns managed through the SPE strategy. [5] Sepsis screenings and antibiotic treatments decreased significantly (from 6.3 to $0.5 \%, p<0.01$ and from 1.2 to $0.5 \%, p<0.01$ respectively). No treatment was delayed. Furthermore, a study carried out in a single centre of Emilia-Romagna reported significant reduction of laboratory tests (from 11.6 to $1.6 \%, p<0.01$ ) and empirical antibiotics (from 2.8 to $0.6 \%, p<0.01$ ) [11]. In a further retrospective study carried out in 3 NICUs of Emilia-Romagna, 2092 full-term and late preterm neonates were managed with SPEs. Among 632 initially asymptomatic neonates at-risk for EOS, only $3 \%$ were evaluated $(0.9 \%$ of the entire cohort) and only $1.1 \%$ ( $0.3 \%$ of the entire cohort) were given empirical antibiotics. No cases of EOS were missed, and no neonates had complications or a worse outcome due to this strategy [12]. Although evidences supporting the SPE based prevention in regions with higher rates of GBS EOS are still lacking, we are convinced that it could be similarly effective.

\section{Discussion}

Here we resume and compare area-based data from 2 Italian regions. They add information for assisting healthcare providers in planning national strategies. As preterm neonates younger than 34 weeks' gestation need special care in NICUs, we focused on late preterm (34-36 weeks' gestation) and full-term ( $\geq 37$ weeks' gestation) neonates, that account for over $90 \%$ of total deliveries and are managed in all birthing centers across country. The recent national survey [4] has shown that great resources are poored into prevention of EOS, and often are given unnecessary antibiotics. Ancillary laboratory tests currently available are low predictive for asymptomatic neonates and have insufficient accuracy for guiding the decision as to whether neonates should be treated with antibiotics [2].

Table 1 Colonization rates and IAP in Emilia-Romagna and Friuli-Venezia Giulia

\begin{tabular}{llll}
\hline & Emilia-Romagna [6-10] & Friuli-Venezia Giulia [5] \\
\hline Years in study & $2003-2005$ & $2009-2012$ & $2005-2006$ \\
Live births & 112,933 & 146,682 & 16,394 \\
Preterm deliveries (\%) & 7.3 & 7.4 & 7.7 \\
Prevention strategy & V-R screening & V-R screening & V-R screening \\
Rates of prenatal screening (\%) & 86.6 & $93.2 \S$ & $89.0 \S$ \\
Rates of vagino-rectal cultures (\%) & 42.7 & $90.4 \S$ & 88.6 \\
Rates of maternal GBS colonization (\%) & $18.1 \S$ & $21.4 \S$ & ND \\
Overall rates of IAP (\%) & 28.7 & 32.0 & $83 \%$ \\
Rates of IAP to women with GBS colonization (\%) & 92.6 & 90.2 & 22.1 \\
Prevalence of risk factors for EOS (\%) & ND & 20.1 & 0 \\
GBS-EOS (cases/1000 live births) & 0.25 & 0.15 & 0 \\
GBS-EOS mortality (cases/1000 live births) & 0.02 & 0.01 & 0 \\
GBS-EOS mortality in full-term neonates, (cases/1000 live births) & 0 & 0 &
\end{tabular}

EOS early-onset sepsis, GBS group B streptococcus, IAP intrapartum antibiotic prophylaxis, $V$ - $R$ vaginorectal $\S$ refers to full term deliveries 
A recent survey carried out in in Europe, North America, and Australia have shown that $14 \%$ of full-term neonates worldwide are evaluated annually for EOS. Furthermore, $8 \%$ of them are treated with antibiotics, although EOS is confirmed only in $0.1 \%$ [13]. The large number of uninfected newborns being evaluated and treated with antibiotics may lead to maternal/infant separation and longer length of stay. Furthermore, antibiotics can increase the risk of resistant pathogens and alter the neonatal microbiome, with risks of health problems in later life (allergies, diabetes, and inflammatory bowel diseases) [13, 14]. However, many infants with mild illness can be observed safely without treatment (unless clinical signs worsen or fail to improve), as they become asymptomatic over the first $6 \mathrm{~h}$. Finally, in a recent and very comprehensive review on risks and benefits of evolving rule-out sepsis practices, [15] Hooven and co-workers estimate (number needed to harm, $\mathrm{NNH}$ ) the potential complications of strategies for managing neonates at risk for EOS. They compare the rare risks of developing severe symptoms of EOS $(\mathrm{NNH}=1610)$ and the more common risks of infiltrate after i.v. infusion $(\mathrm{NNH}=7)$ or delayed breastfeeding $(\mathrm{NNH}=2.9)$. Investigators conclude that there is strong evidence to support observation-based approaches for managing neonates at risk for EOS.

\section{Conclusion}

The SPEs strategy has proven sensitive for timely detection of all cases of EOS, not only for GBS sepsis. By providing strong assurance that frequent examinations actually are performed, this strategy seems safe, reliable and easy to perform. Strategies reducing neonatal hospitalization during the first week life, respecting the bonding of mother and infant, and minimising unnecessary antibiotics must be taken into consideration.

\section{Abbreviations}

EOS: Early-onset sepsis; GBS: Group B streptococcus; IAP: Intrapartum antibiotic prophylaxis; NICU: Neonatal intensive care unit; NNH: Number needed to harm; SPE: Serial physical examinations

\section{Aknowledgments}

We thank the GBS Prevention Working Group of Emilia-Romagna (components are listed below): L. Memo, G. Nicolini (Ospedale San Martino, Belluno); M. Ciccia, A. Bastelli, F. Sandri (Ospedale Maggiore, Bologna); S. Ambretti, M.G. Capretti, L. Corvaglia, A. Dondi, M. Lanari, L. Pasini, L. Ragni, (Policlinico Sant'Orsola, Bologna); A. Albarelli (Ospedale Santa Maria, Borgo Taro); V. Fiorini, C. Giugno, P. Lanzoni (Ospedale B. Ramazzini, Carpi); E. Di Grande, A. Polese (Ospedale Sant'Anna, Castelnuovo Monti); M.C. China, V. Rizzo, M Stella (Ospedale M. Bufalini, Cesena); A. Zucchini (Ospedale Civile, Faenza); L. Malaguti (Ospedale del Delta, Ferrara); M. Azzalli, G. Garani, C. Lama (Ospedale Sant'Anna, Ferrara); S. Nasi, P. Bacchini, G. Fragni (Ospedale di Vaio, Fidenza); P. Baldassarri, R.M. Pulvirenti, E. Valletta, V. Venturoli (Ospedale Morgagni-Pieratoni, Forli); C. Alessandrini, M.L. Bidetti, S. Storchi Incerti (Ospedale Civile, Guastalla); C. Di Carlo, A. Lanzoni, L. Serra, D. Silvestrini (Ospedale Santa Maria della Scaletta, Imola); A. Berardi F. Facchinetti, F. Ferrari, L. Lugli, C. Venturelli (Azienda Ospedaliera Policlinico, Modena); M. Sarti (Ospedale Baggiovara, Modena); A. Volta (Ospedale Franchini, Montecchio Emilia); I. Dodi, L. Gambini, C. Magnani (Ospedale Policlinico, Parma); B. Guidi (Ospedale Civile, Pavullo); M. Bertelli, G. Biasucci, R. Chiarabini,
}

N. De Paulis, D. Padrini, S. Riboni (Ospedale G. da Saliceto, Piacenza); M.F. Pedna, V. Sambri (Laboratorio Area Vasta Emilia-Romagna, Pievesestina); L. Casadio, F. Marchetti, C. Muratori, G. Piccinini, C. Renzelli (Ospedale Santa Maria delle Croci, Ravenna); S. Amarri, L. Baroni, E. Carretto, S. Fornaciari, G. Gargano, S. Pedori, M. Riva, C. Zuelli (Ospedale Santa Maria Nuova, Reggio Emilia); G. Ancona, S. Bolognesi, I. Papa, G. Vergine, L. Viola (Ospedale Infermi, Rimini); C. Chiossi, R. Pagano, C. Rivi, C. Zanacca (Ospedale Civile, Sassuolo); C. Bonvicini, R. Palmieri (Ospedale C. Magati, Scandiano).

\section{Availability of data and materials}

The datasets used and/or analysed during the current study is available from the corresponding author on reasonable request.

\section{Authors' contributions}

$A B$ conceptualized and designed the study, critically reviewed the manuscript, and approved the final manuscript as submitted. $A B$ and $C T$ designed the data collection instruments, contributed to distribution and follow-up of the survey, carried out the initial analyses, drafted the initial manuscript, reviewed, revised and approved the final manuscript as submitted. LT JB DS MA CS contributed to distribution and follow-up of the survey, reviewed and revised the manuscript, and approved the final manuscript as submitted. LC reviewed and revised the manuscript, and approved the final manuscript as submitted. All authors approved the final manuscript as submitted and agree to be accountable for all aspects of the work.

\section{Ethics approval and consent to participate}

Not applicable.

\section{Consent for publication}

Not applicable.

\section{Competing interests}

The authors declare that they have no competing interests. Dr. Alberto Berardi has received funding from the Agenzia Sanitaria Regione dell'Emilia-Romagna: "Assegnazione e concessione di finanziamenti alle Aziende Sanitarie Regionali per la realizzazione di programmi di interesse regionale a sostegno del Piano Regionale della Prevenzione 2015-2018 C.U.P. n. E43G17000680002".

The remaining authors declare they have no funding source.

Financial disclosure: Dr. Alberto Berardi has received fees from these Companies: Pfizer.

(2015), Putnam Associates (2016) and GSK (2017).

\section{Publisher's Note}

Springer Nature remains neutral with regard to jurisdictional claims in published maps and institutional affiliations.

\section{Author details \\ ${ }^{1}$ Unità Operativa di Terapia Intensiva Neonatale, Dipartimento Integrato Materno-Infantile, Azienda Ospedaliero-Universitaria Policlinico, Modena, Italy. ${ }^{2}$ Neonatologia, Patologia Neonatale e Terapia Intensiva Neonatale, Fondazione IRCCS Policlinico "San Matteo", Pavia, Italy. "Unità Operativa di Terapia Intensiva Neonatale, IRCCS "Burlo Garofolo", Trieste, Italy. "Struttura Complessa di Pediatria e Neonatologia, Azienda Ospedaliera Santa Maria degli Angeli, Pordenone, Italy. ${ }^{5}$ Unità Operativa di Terapia Intensiva Neonatale, Ospedale S. Anna, Ferrara, Italy. ${ }^{6}$ Scuola di specializzazione in Pediatria, Università di Modena e Reggio Emilia, Azienda Ospedaliero-Universitaria Policlinico, Via del Pozzo, 71 -, 41124 Modena, MO, Italy.}

Received: 7 March 2018 Accepted: 21 June 2018

Published online: 28 June 2018

\section{References}

1. Verani JR, McGee L, Schrag SJ. Division of bacterial diseases, National Center for Immunization and Respiratory Diseases, Centres for disease control and prevention (CDC). Prevention of perinatal group B streptococcal disease revised guidelines from CDC, 2010. MMWR Recomm Rep. 2010;59(RR-10):1-36.

2. Benitz WE, Wynn JL, Polin RA. Reappraisal of guidelines for management of neonates with suspected early-onset sepsis. J Pediatr. 2015;166:1070-4. 
3. Hughes RG, Brocklehurst P, Steer PJ, Heath P. Stenson BM on behalf of the Royal College of Obstetricians and Gynaecologists. Prevention of early-onset neonatal group B streptococcal disease. Green-top guideline no. 36. BJOG. 2017:124:e280-305. Accessed at 2 Mar 2017

4. Tzialla C, Berardi A, Farina C, Clerici P, Borghesi A, Viora E, et al. Task force for group B streptococcal infections for the Italian Society of Neonatology; Italian Society of Obstetricians and Gynecologists; Italian Association of Clinical Microbiologists. Strategies for preventing group B streptococcal infections in newborns: a nation-wide survey of Italian policies. Ital J Pediatr. 2017;43:98.

5. Cantoni L, Ronfani L, Da Riol R, Demarini S. Physical examination instead of laboratory tests for most infants born to mothers colonized with group B Streptococcus: support for the Centers for Disease Control and Prevention's 2010 recommendations. J Pediatr. 2013;163:568-73.

6. Berardi A, Lugli L, Rossi C, Guidotti I, Lanari M, Creti R, et al. Impact of perinatal practices for early-onset group B streptococcal disease prevention. Pediatr Infect Dis J. 2013;32:e265-71.

7. Berardi A, Lugli L, Baronciani D, Creti R, Rossi K, Ciccia M, et al. GBS prevention working Group of Emilia-Romagna.. Group B streptococcal infections in a northern region of Italy. Pediatrics. 2007;120:e487-93.

8. Berardi A, Di Fazzio G, Gavioli S, Grande E, Groppi A, Papa I, et al. Universal antenatal screening for group B streptococcus in Emilia-Romagna. J Med Screen. 2011:18:60-4.

9. Berardi A, Baroni L, Bacchi Reggiani ML, Ambretti S, Biasucci G, Bolognesi S, et al. GBS prevention working group Emilia-Romagna.. The burden of earlyonset sepsis in Emilia-Romagna (Italy): a 4-year, population-based study. J Matern Fetal Neonatal Med. 2016;29:3126-31.

10. Berardi A, Rossi C, Bacchi Reggiani ML, Bastelli A, Capretti MG, Chiossi C, et al. An area-based study on intrapartum antibiotic prophylaxis for preventing group B streptococcus early-onset disease: advances and limitations. J Matern Fetal Neonatal Med. 2017;30:1739-44.

11. Berardi A, Fornaciari S, Rossi C, Patianna V, Bacchi Reggiani ML, Ferrari F, et al. Safety of physical examination alone for managing well-appearing neonates $\geq 35$ weeks' gestation at risk for early-onset sepsis. J Matern Fetal Neonatal Med. 2015;28:1123-7.

12. Berardi A, Buffagni AM, Rossi C, Vaccina E, Cattelani C, Gambini L, Baccilieri $F$, et al. Serial physical examinations, a simple and reliable tool for managing neonates at risk for early-onset sepsis. World J Clin Pediatr. 2016;5:358-64.

13. van Herk W, el Helou S, Janota J, Hagmann C, Klingenberg C, Staub E, et al. Variation in current Management of Term and Late-preterm Neonates at risk for early-onset Sepsis: an international survey and review of guidelines. Pediatr Infect Dis J. 2016:35:494-500.

14. Tzialla C, Borghesi A, Serra G, Stronati M, Corsello G. Antimicrobial therapy in neonatal intensive care unit. Ital J Pediatr. 2015;41:27.

15. Hooven TA, Randis TM, Polin RA. What's the harm? Risks and benefits of evolving rule-out sepsis practices. J Perinatol. 2018;26 [Epub ahead of print]

\section{Ready to submit your research? Choose BMC and benefit from:}

- fast, convenient online submission

- thorough peer review by experienced researchers in your field

- rapid publication on acceptance

- support for research data, including large and complex data types

- gold Open Access which fosters wider collaboration and increased citations - maximum visibility for your research: over $100 \mathrm{M}$ website views per year

At BMC, research is always in progress.

Learn more biomedcentral.com/submissions 